
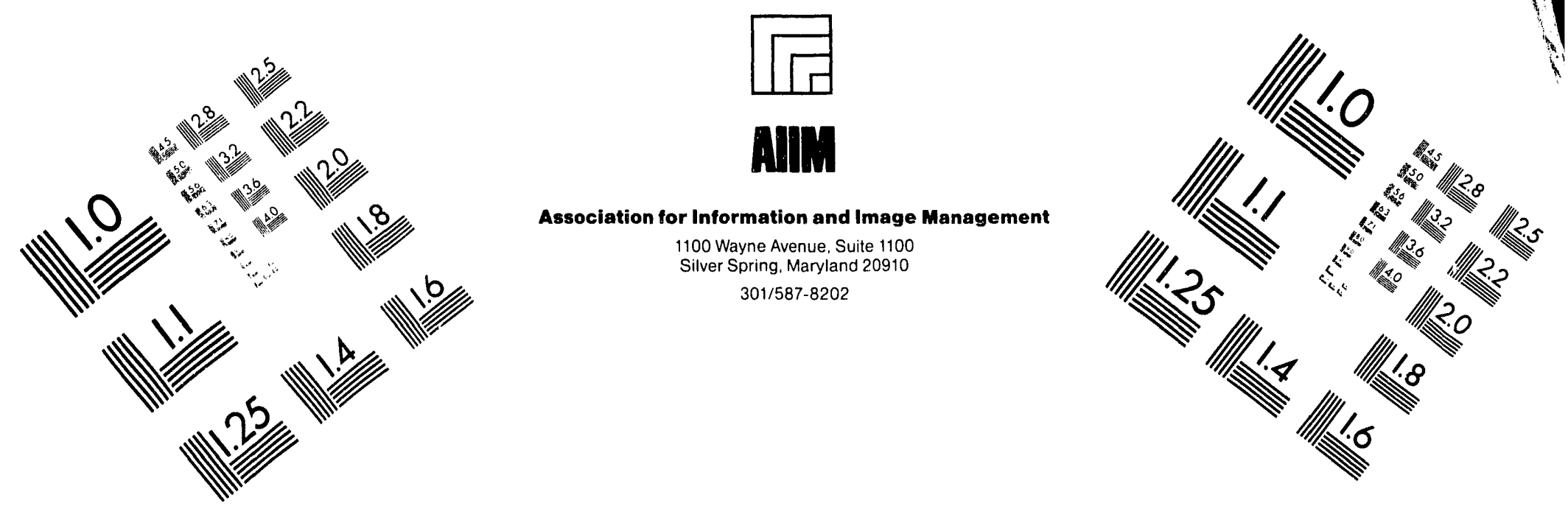

\title{
Centimeter
}

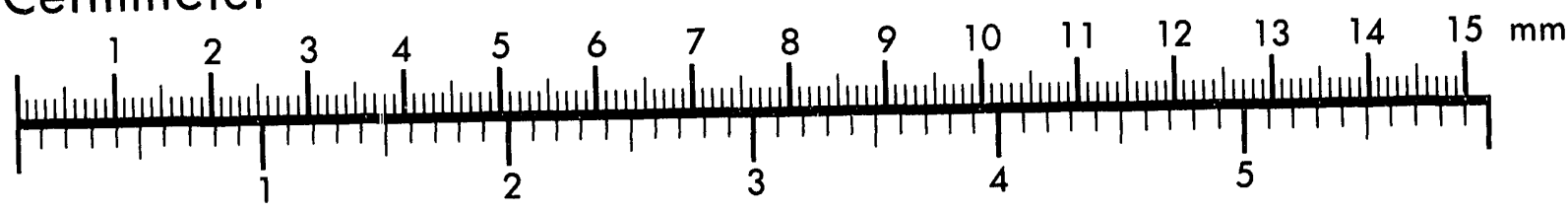
Inches
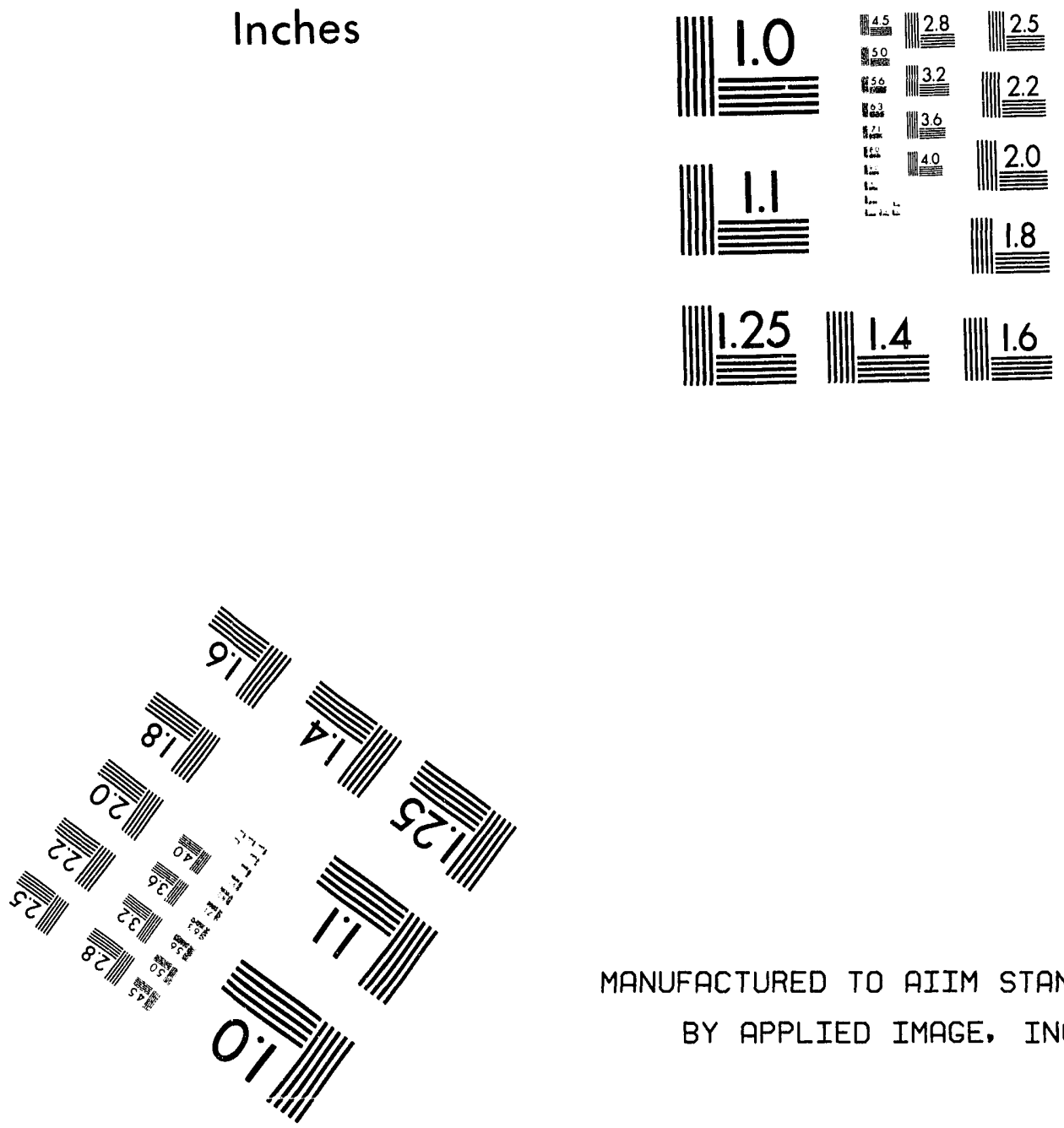

MANUFACTURED TO AIIM STANDARDS

BY APPLIED IMAGE, INC.

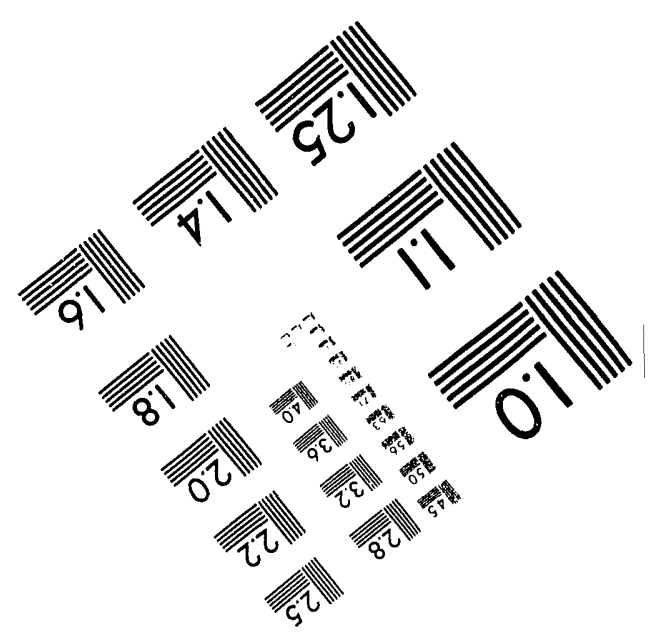



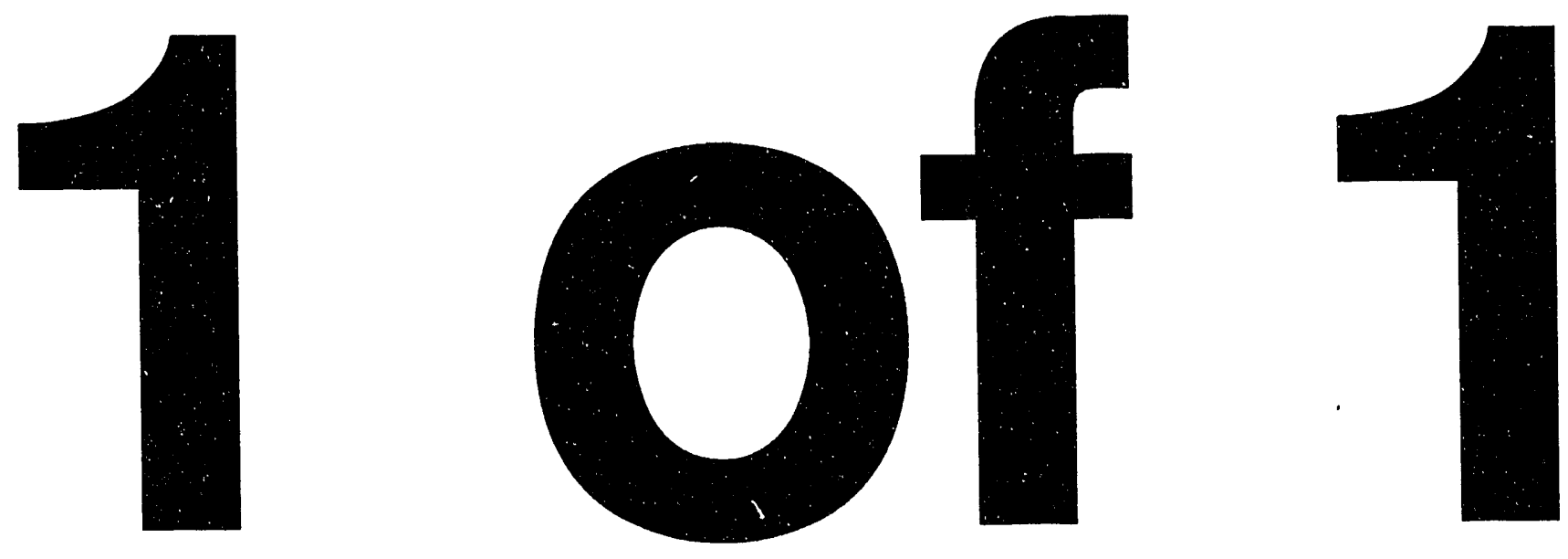


\section{Digital Control Systems in Nuclear Power Plants: \\ FAILURE INFORMATION, MODELING \\ CONCEPTS, AND APPLICATIONS}

William J. Galyean

June 1993

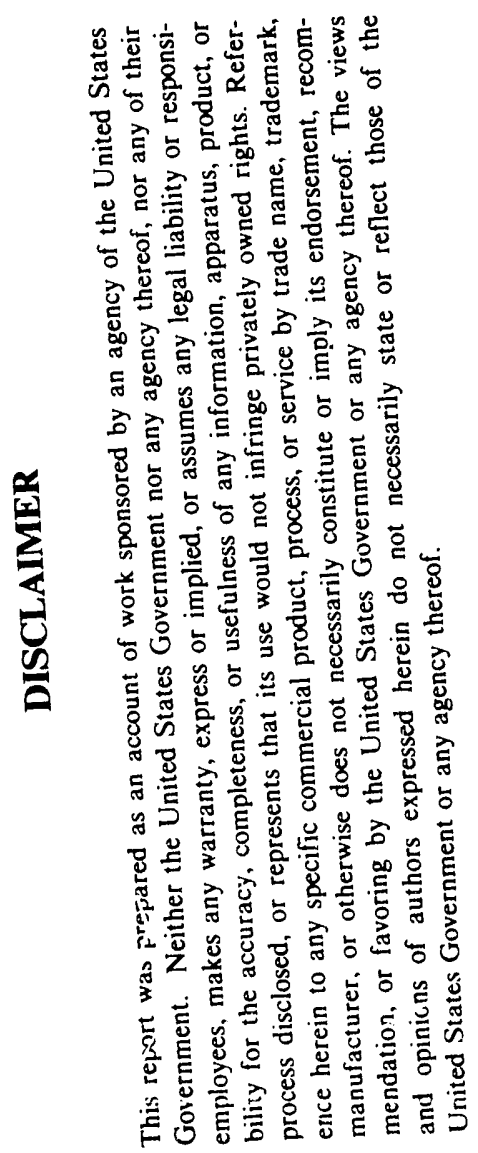

Idaho National Engineering Laboratory
EG\&G Idaho, Inc.
Idaho Falls, Idaho 83415

Prepared for the Division of Systems Research Office of Nuclear Regulatory Research

U. S. Nuclear Regulatory Commission

Washington, D. C. 20555 Under DOE Idaho Field Office Contract DE-AC07-76ID01570

FIN L1123

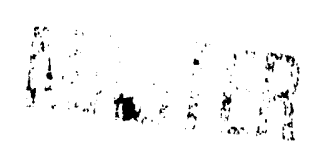




\begin{abstract}
This report briefly describes some current applications of advanced computerized digital display and control systems at U. S. commercial nuclear power plants and presents the results of a literature search that was made to gather information on the reliability of these systems. Both hardware and software reliability were addressed in this review. Only limited failure rate information was found, with the chemical process industry being the primary source of information on hardware failure rates and expert opinion the primary source for software failure rates. Safety-grade digital control systems are typically installed on a functional like-for-like basis, replacing older analog systems without substantially changing interactions with other plant systems. Future work includes performing a limited probabilistic risk assessment of a representative DCS to assess its risk significance.
\end{abstract}




\section{CONTENTS}

ABSTRACT ........................... . .

ACRONYMS ........................... v v

GLOSSARY ........................... . . vi

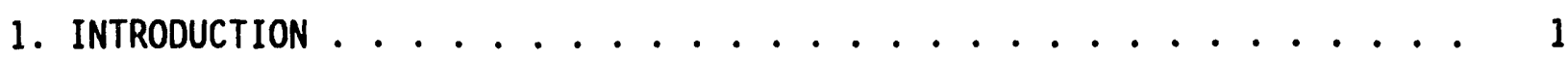

2. DCS CHARACTERISTICS AND CONFIGURATIONS ............... 2

3. SPECIFIC APPLICATIONS OF COMPUTERIZED SYSTEMS . . . . . . . . . 4

3.1 Woodward Control System . . . . . . . . . . . . . 5

3.2 B\&W Plant Control System .................. . 6

3.3 Emergency Feedwater Instrumentation and Control System . . . . 7

3.4 Eagle-21 Process Protection System .............. 8

4. DCS SOFTWARE AND HARDWARE RELIABILITY . . . . . . . . . . . . 11

4.1 Software Reliability . . . . . . . . . . . . . . . 11

4.2 Hardware Reliability . . . . . . . . . . . . . . 15

5. PRA MODELING OF DCS ............................ 20

5.1 Introduction ................... . . 20

5.2 Outline of Analysis Plan ................ . . 22

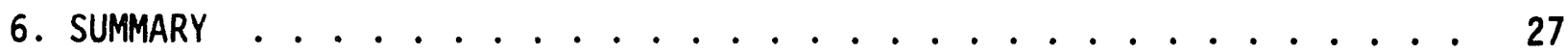

7. REFERENCES . . . . . . . . . . . . . . . . . . . 28

Appendix A - Westinghouse Process Protection System History . . . . . . 30

Appendix B - Canadian DCS Experience . . . . . . . . . . . . . 31

Appendix C - Bibliography . . . . . . . . . . . . . . . . 34 


\section{FIGURES}

1. Westinghouse Eagle-21 Microprocessor-Based Process Protection System. 10

2. Top logic of DCS fault tree (sheet 1 of 3). . . . . . . . 24

2. Top logic of DCS fault tree (sheet 2 of 3 ).......... 25

2. Top logic of DCS fault tree (sheet 3 of 3 ) ......... 26

\section{TABLES}

1. Mean time between failure (MTBF) summary for DCS components in the South Texas Units 1 \& 2 Qualified Display Processing System (for period $8 / 87$ to $11 / 90)$. . . . . . . . . . . . . . 17

2. Summary of failure data for redundant industrial computer systems. 18

3. Failure rate estimates for DCS components. . . . . . . . . 19

A-1. U.S. NPP experience with the Eagle-21 system. . . . . . . . 30 


\section{ACRONYMS}

$\begin{array}{ll}\text { CCF } & \text { commom cause failure } \\ \text { CPI } & \text { chemical process industry } \\ \text { DCS } & \text { digital control system } \\ \text { DRIML } & \text { dual redundant input module logic } \\ \text { F-T } & \text { fault-tolerant } \\ \text { HIFT } & \text { hardware implemented fault tolerance } \\ \text { PDS } & \text { plant display system } \\ \text { PES } & \text { programmable electronic system } \\ \text { PLC } & \text { programmable logic controller } \\ \text { QDPS } & \text { Qualified Display Processing system } \\ \text { RTD } & \text { Resistance Temperature Detector } \\ \text { SIFT } & \text { software implemented fault tolerance } \\ \text { TMR } & \text { triple modular redundancy } \\ \text { TRIML } & \text { triple redundant input module logic } \\ \text { V\&V } & \text { Verification and Validation }\end{array}$




\section{GLOSSARY}

voter

mask

like-for-like
General term used to describe methods of pooling outputs as an implementation of fault tolerance. Voting can employ either an acceptance test (e.g., recovery blocks), a comparator (e.g., $\mathrm{N}$-version programming in which at least three channels are operating concurrently and if two or more result in the same output value that value is selected as the system output), or the selection of a median value.

Refers to the fundamental feature of fault tolerance whereby single channel failures are overcome in an operational sense. This does not affect the fault detection aspect which would be a function of the system design (i.e., faults would continue to be annunciated depending on how the system was designed to do so).

This term is used in the context of the current program, namely the effect of the modification on the risk posed by NPP operation. Because the way the plant responds to any type of emergency or accident condition is not substantially different after the modification compared to before, it is termed a "like-for-like" replacement. That is, replacing an analog "black box" with a digital "black box," while leaving the inputs and outputs for the black box the same, is referred to as a like-for-like replacement. 


\section{Digital Control Systems in Nuclear Power Plants: \\ Fatlure Information, Modeling CONCEPTS AND APPLICATIONS}

\section{INTRODUCTION}

This report documents an effort to understand the current nuclear power plant (NPP) industry practice in adopting advanced computerized display and control systems. Ultimately, the objective is to quantify the effect of these systems on risk. The information presented here will provide the background for a probabilistic risk assessment (PRA) sensitivity analysis that will quantify the effect of a specific NPP system application.

An extensive literature search was performed as a part of this effort. (See Appendix C for a bibliography of items reviewed.) Unfortunately, little of this information is relevant to the scope of this program, namely the risk significance of digital control systems (DCSs) in U.S. commercial NPPs. This is because most of the reports describe methods for assessing system reliability rather than actual reliability data or experience. This includes information from the U.K. Systems Reliability Directorate where current efforts are aimed at developing tools for assessing software reliability. ${ }^{1}$ The best source of information on system architecture and operating experience (including failure data and rates) is the chemical process industry (CPI), where DCSs and programmable logic controllers (PLCS) have been in use for a number of years.

In the nuclear power industry the primary motivation for replacing older analog control systems with new digital technology is the obsolescence of the old analog equipment. Approximately $80 \%$ of the nuclear plants in the U.S. are operating with hardware that is no longer fully supported by the equipment manufacturer. ${ }^{2}$ This means that replacement parts and technical support are not available for many older analog systems. Despite this problem, most utilities have shown a strong tendency to continue with the existing analog 
systems. To a large degree this is attributed to a natural tendency to resist change, relatively good experience with the equipment, and by a reluctance to embark on a licensing change with the NRC."

The following sections present an overview of the issues relevant to understanding the effect of incorporating DCSS on NPP risk. Section 2 is a general discussion of the characteristics and configurations of DCSs, followed in Section 3 by a brief description of some specific DCSs found in commercial NPPs. Section 4 presents information found in the literature on the reliability of DCS software and hardware. Finally, Section 5 is a discussion of a proposed approach to modeling a DCS in a PRA.

\section{DCS CHARACTERISTICS AND CONFIGURATIONS}

Safety-grade ${ }^{b}$ DCSs are typically designed using fault-tolerant architecture, the goal being to enhance reliability by allowing the system to continue operating even after one or more component failures. Theoretically, the reliability of such systems can be extremely high. However, for some specific designs, common cause failures (CCF) and single point failures (i.e., non-redundant components such as input/output modules) limit the level of

a. This characterization was expressed in a paper made at an EPRI workshop titled: "Advances in Computers, Controls, and Automated Technologies for Power Plants," that took place on February 5-7, 1992 in San Diego. The paper was authored by the following: R. J. Burroni, New York Ppwer Authority; T. J. Galloway and i. N. Kowalchuk, Northeast Utilities; J. T. Keiper, The Foxboro Company; D. A. Kulp and D. A. Mitchel, Yankee Atomic; and G. Nohed, Swedish State Power Board.

b. In simple terms, a safety system is any system that is taken credit for by the Ticensee in their Final Safety Analysis Report (FSAR). Technically, it is any system relied upon by the licensee to show compliance with the General Design Criteria for Nuclear Power Plants (10CFR50 Appendix A). In practical terms, if the system is reflected in safety calculations used for verifying the plant can safely withstand a design basis accident, it is considered a safety system. Not all DCSs are safety grade, for example, digital feedwater control systems are not. However, in the context of the current project, namely, evaluating the risk significance of DCS in commercial NPPS, the primary interest is on safety grade DCSs. 
reliability achievable to just very high. ${ }^{c}$ Although fault-tolerant controllers might not achieve extremely high reliability, data show that the mean time to system failure of fault-tolerant controllers is approximately eight times that of single-channel controllers. ${ }^{3}$

Fault-tolerant process control systems commonly have either dual redundancy or triple modular redundancy (TMR), "which in turn can be either synchronous or asynchronous. Systems with dual redundancy have two channels: one designated as a primary and the other as a standby channel. Such a system relies upon internal diagnostics to detect a failure of the primary channel and then to switch the control function to the standby channel. In the synchronous form of the dual redundant system, the clocks of the two channels are synchronized, with both channels executing identical application software simultaneously. The two outputs are compared and if they are identical, the primary channel retains control. If the outputs differ, each computer performs internal diagnostic checks to identify the failed channel. The system then reconfigures to designate the operating (i.e., nonfailed) channel as the primary one. In contrast, the asynchronous system operates on a single (primary) channel until a fault is detected. Control is then switched to the standby channel, which can be either active (i.e., operating concurrently with the primary) or passive (i.e., merely reading input from the primary channel during normal operations).

c. In EPRI report TR-100803, $\mathrm{Tab}^{\prime} 36.2$, the authors compare the results of reliability analyses of dual redundant and TMR systems with various assumptions on the potential for common cause failures (CCF), and the effectiveness of fault detection and recovery. Mean-times-to-system-failure (MTSF) range from 2.3 years for a dual redundant system with potential CCFs and imperfect fault detection and recovery to 260,000 years for a TMR system without CCFs and with perfect fault detection and recovery. On this basis, a reasonable but somewhat arbitrary distinction between extremely high and very high reliability might be a MTSF of 1,000 years.

d. Notable exceptions to this categorization are digital reactor protection systems, which in keeping with the notion of like-for-like replacement of the older analog systems, follow the 2-out-of-4 logic structure of the analog systems. 
The TMR system operates with all three channels in service and uses an output voting scheme to select a single output (e.g., the median value) that is used by the output module. The TMR synchronous and asynchronous systems are similar in that all three channels are active. The difference manifests itself in the voter. In asynchronous systems, because information processing and signal generation are not synchronized, the voting must be done in software [software-implemented fault tolerance (SIFT)]; in synchronous systems, the voting can be done in hardware [hardware-implemented fault tolerance (HIFT)]. HIFT is the faster of the two methods; however, SIFT allows the use of nonidentical software in the redundant channels and offers more flexibility in the design of the control logic.

There appears to be a large amount of diversity in the specific configurations within a particular type of fault tolerant $(F-T)$ DCS. For example, a dual redundant system might or might not include redundancy in the I/O modules, or some TMR systems might rely on a single (i.e. nonredundant) module to perform the voting of the three redundant channels. These potential single points of failure would exist in addition to any possible common cause or common mode failures that might arise from such things as using identical software or hardware in the redundant channeis. Thus, careful understanding and modeling of the specific system will be necessary to accurately assess its susceptibility to failure.

\section{SPECIFIC APPLICATIONS OF COMPUTERIZED SYSTEMS}

Advanced, computerized system applications in present-generation NPPs typically take two forms. First, there are the information-only, advanced display systems (AdDS). In many cases, when a modification is made to add an AdDS to an NPP, the older equipment is left in place. Therefore, in these situations since the operators have the option of reverting to the premodification mode of operation, the AdDS supplements, but does not replace, the existing instrumentation. The implication of this is, operator performance should not be any worst after the modification compared to before. 
AdDSs are commonily not safety grade. Examples of this type of system are: Safety Parameter Display System (SPDS), Core Operating Limit Supervisory System (COLSS), and Plant Monitoring System (PMS). The second type of application is the DCS, which typically replaces an existing analog system and can, if desired, provide more enhanced features and capabilities. Generally, new sensors and instrumentation are used instead of re-calibrating existing equipment and tracing existing cables. DCSs can appear in both safety system applications (such as emergency safety feature actuation system and auxiliary feedwater control system) and non-safety grade applications (such as main feedwater control systems). Examples of safety grade DCSs are the Emergency Feedwater Initiation and Control (EFIC) system that has been installed at Arkansas Nuclear One Unit-1, and the Westinghouse Eagle-21 system.

This section briefly describes some of the current applications of DCSs in commercial NPPS. To estimate the impact of a DCS on plant risk it is necessary to understand the specific functions of the DCS in plant operation. Hence, the information below is essential background for assessing the risk associated with a particular DCS.

\subsection{Woodward CONTrol System}

The information presented in this section is extracted from Reference 4, which describes the modification of the Haddam Neck auxiliary feedwater (AFW) controls to incorporate the Woodward 501 Digital Control System. Haddam Neck is a 4-10op Westinghouse plant that went into commercial operation in January 1968 .

The function of the Woodward 501 Digital Control System is to start and bring the AFW Terry Turbines up to rated speed upon receipt of an AFW automatic initiation signal. Once the turbines are running, the control system will execute a firmware algorithm that uses steam inlet pressure, turbine speed, and pump discharge pressure as inputs to ensure adequate AFW flow. 
The software portion of the Model 501 Digital Control System controls the speed, discharge pressure, and steam inlet pressure of the turbine driven AFW pump. The software will not actuate AFW or contror the position of the main feedwater regulating bypass valves.

A DCS is installed on each of the AFW turbines, with each single channel system comprises a chassis, CPU module, system input/output (SI/0) moduie, contact input module, contact output module, analog input module, analog output module, magnetic-pickup-unit/analog output module, relay interface module, and two redundant power supplies.

A Woodward Governor Company experience iist and reliability estimate for the Model 501 Digital Control System, identifies more than 100 applications of this system over a 9-year period and estimates a mean-time-between-failure (MTBF) of 3.69 years on the "weakest link" component [Reference 4, p. B7].

\section{2 b\&W Plant Control System}

The primary purpose of the B\&W advanced Plant Control System (PCS) is to control those plant processes and components currently controlled by the Integrated Control System (ICS). Additional control functions presently contained within the Non-Nuclear Instrumentation (NNI) system that affect primary system pressure, temperature, and inventory also will be incorporated into the PCS. Development of this system has been a project of the B\&W Owners Group (BWOG) since 1987. In February 1991, the BWOG selected Foxboro as the hardware vendor with Oak Ridge National Laboratory developing the software. The information in this section has been extracted from References 5 and 6 .

The PCS architecture consists of three redundant channels of microprocessor-based modules. This triple modular redundancy (TMR) masks the failure of any individual channel until it can be repaired. Furthermore, a single channel can maintain plant control if the remaining channels are inoperative or bypassed. The voting system, supplied by the Triconex 
Corporation, reads the outputs from the three channels, selects the median value, and sends that to the final control element.

Triply redundant hardware is supplied by the Foxboro Company. The design specification required a system availability of not less tiran $99.998 \%$ and a minimum predicted mean time to failure (MTTF) for the system of 40 years. (Note that this combination of availability and MTTF implies a maximum meantime-to-repair of 7 hours. Specifically, these requirements limit the system to one system failure over a 40-year duration and the system can be unavailable for no more than 7 hours.)

\subsection{Eniergency feedwater Instrumentation and Control System}

A few years ago ANO-1 (a B\&W plant) retrofit a new digital control system for the Emergency Feedwater (EFW) System called the Emergency Feedwater Instrumentation and Control (EFIC) system. This system has various plant inputs and functions, with its primary function being the initiation and control of EFW. Previously, the EFW system was initiated and controlled manually by a control room operator.

The EFIC system receives level and pressure inputs from the once-through steam generators (OTSGS). These level and pressure taps were installed specifically for the EFIC system; they are separate from other plant instrumentation. The level instrumentation has a wide range and a narrow range. In addition, the EFIC system receives information from the reactor protection system (RPS) on the status of the reactor coolant pumps (RCPs), i.e., running or not.

e. The information in this section is based on discussions with a former ANO1 shift supervisor. ANO-1 is a lower-loop B\&W plant that installed a digital control system for the emergency feedwater system called the Emergency Feedwater Instrumentation and Control (EFIC) system. 


\subsection{Eagle-21 Process Protection System}

The Westinghouse Eagle-21 process protection system is a modularmicroprocessor based upgrade for older analog equipment in commercial NPPs (see Appendix A for a brief history on Westinghouse process protection systems). This system uses instrument and sensor readings to generate valid signals for the reactor protection system (RPS) and the engineered safeguard feature actuation system (ESFAS). The level of redundancy is determined by the particular system receiving the Eagle-21 signals. For example, the RPS requires four redundant channels (for two out of four logic), while most ESFAS actuations require three redundant channels (e.g., safety injection system requires two out of three logic). Features of the Eagle-21 system include:

1. Automatic surveillance testing to significantly reduce the time required to perform surveillance tests.

2. Self-calibration to el iminate rack drift and time-consuming calibration procedures.

3. Self-diagnostics to reduce the time required for troubleshooting.

4. Significant expansion capabilities to easily accommodate functional upgrades and plant improvements.

5. Modular design to allow for phased installation into existing process racks and use of existing field terminations.

The Eagle-2l system hardware, which is installed in a single rack or cabinet, corsists of three basic subsystems per channel. These are the Loop Processor Subsystem, Tester Subsystem, and Input/Output Subsystem (see Figure 1).

The input portion of the $1 / 0$ subsystem consists of customized analog input and contact input signal conditioning modules. The output portion consists of analog output, contact output, and partial trip output modules.

The Loop Processor Subsystem executes all of the algorithms and makes comparisons for the protective functions. It consists of a digital filter processor, loop calculation processor, communication controller, digital I/0 modules, and a digital-to-analog (D/A) converter. 
The Tester Subsystem is the focal point of human interaction with the protection system. Together with the Man-Machine-Interface (MMI) test cart (basically an IBM-compatible personal computer that plugs into the MMI), ic provides the interface that allows personnel to adjust setpoints and tuning constants and to perform surveillance tests on the protection system. The Tester Subsystem consists of a test sequence processor, communication controller, digital-to-analog converter module, and a digital I/0 module. 


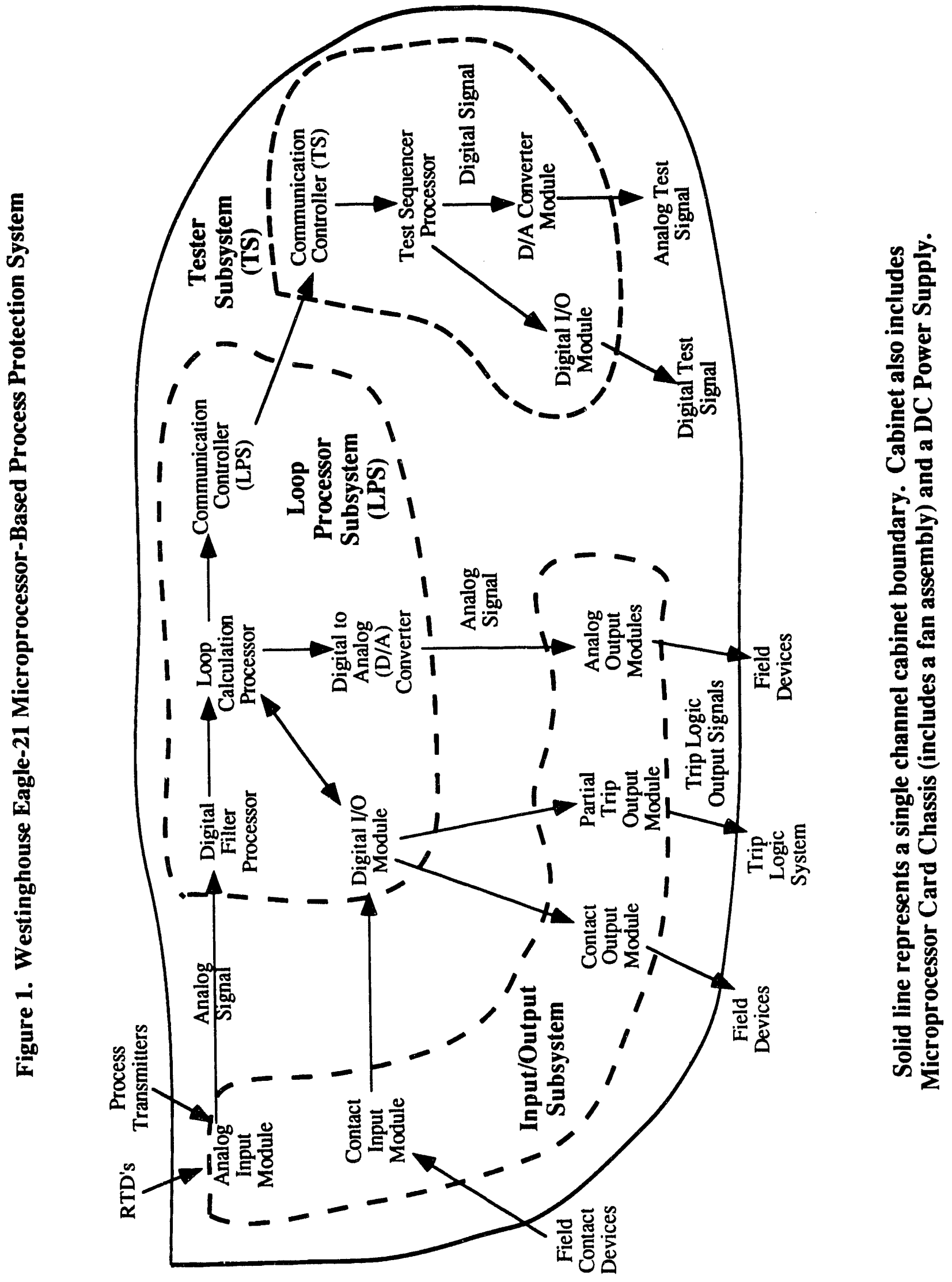




\section{DCS SOFTWARE AND HARDWARE RELIABILITY}

This section discusses the reliability of both computer software and hardware used in DCSs. Some sparse data is available on computer hardware reliability but less could be found on software. As discussed in the following section, most of the literature on software reliability deals with methods for performing V\&V, which is done by the vendors. The data and failure rates obtained from these V\&V processes are considered proprietary and are not available in the literature. Reliability requirements are typically included in purchase specifications. However, these requirements are made with respect to the entire system and do not make a distinction between software and hardware faults. Therefore, some of the data presented in the section on hardware reliability were gathered on system performance as a whole and will include failures caused by faults in the software.

\subsection{SOfTWARE RELIABILITY}

Limited data is available on the reliability of computer software. Literature searches conducted on this topic have produced only sparse data on failure rates. Although much work has been done in the field of software reliability, it mostly deals with methods for assessing and assuring reliability (e.g., via the V\&V process), not actual reliability evaluations. Typically, software developers and vendors will assess a code's reliability through testing. There are many techniques for estimating the reliability of a software package. Reference 7 reviews the various methods available. For example, one method (reliability growth model) measures the mean-timesbetween-failure (MTBF) of the code during the testing phase. Failures are collected and plotted and when the extrapolated MTBF yields an acceptable result (e.g., with respect to the design requirements), the code is released to the customer. This type of information is maintained by the developers, but is not readily available to outside interests. There are also a few deterministic models based on some measure of the "complexity" of the code (e.g., the number of lines in a code, number of operators, and number of operands). A variety of parameters are measured for a particular piece of 
software, then combined through a simple mathematical formula to determine the size or complexity of the code. This metric is then used as a basis for estimating the fault density of the program (i.e., number of faults per 1,000 lines of code). However, this is the fault density at the beginning of the V\&V program, not for the code that is actually put into use by the customer.

One paper ${ }^{\theta}$ explains the paucity of data from which to fashion statistical predictions as follows:

"... Information on software failure is seldom made public. Companies fear that sharing such knowledge would harm their competitive stance. They worry even more that publishing it would antagonize public opinion. People might see the detection of a software fault as an indication of low production standards, even though it may actualiy attest to a very thorough procedure applied to very high quality software..."

The authors of the above also cite a few reliability requirements for software systems. The U.S. FAA requires its new air-traffic control system to have an unavailability of less than 3 seconds a year. In civilian airliners, the probability of certain catastrophic failures must be no worse than $10^{-9}$ per hour. Because of the difficulty in assuring high reliability of software in critical applications, one approach cited in Reference 8 describes a philosophy that systems be designed such that the role of software is "not too critical." Then the reliability requirements can be sufficiently modest that they can be proved before the system is deployed. This approach has been taken for the new Sizewell B plant in the U.K., where only a $10^{-4}$ probability of failure on demand is required for the software-based protection system.

Assuring high reliability of software is a very difficult task. No matter how extensive the testing, there are always questions about its completeness, both for the inputs tested and the possible paths exercised. According to two experts in the field, ${ }^{9}$ currentiy existing approaches to quantitative assessment of software reliability have a practical failure rate limit of about $10^{-4} / \mathrm{h}$ for preoperational software. This limit is based on the practical problems associated with testing software for 10,000 hours. 
In the literature, discussions on software V\&V will include a characterization of the types of faults or errors encountered that require correction. Even mistakes in comment coding and output that deviate only slightly are sometimes counted in the process, which would make it difficult to extrapolate a functional reliability for the software. Other projects categorize errors as major or minor. IEEE/ANSI Standard 982.2 differentiates among different types of problems in software by defining:

Errors - incorrect software (human error). An error is any human mistake that results in incorrect software; errors include omission of a critical requirement in a software specification, a developer's misinterpretation of the requirement, or an incorrect translation from design to code. Fauits - bugs (possibly result of errors). A fault is an error's manifestation in software that causes a functional unit of the software system to fail in performing its required function; sometimes called a "bug," a fault is a part of the code that needs to be fixed. Defects - anomalous product (possibly result of fault). A defect is an anomaly in any intermediate or final software product resulting from an error or fault, ranging from an incorrectly specified set of test data to an incorrect entry in user documentation.

Failures - loss of required function (possibly result of defects). A failure is the inability of a functional unit of the system depending on the software to perform its required function, or to perform the function within required limits

Software poses some unique characteristics that affect its reliability and factor into reliability estimates. Foremost is that software does not "wear out." A particular software package leaves the vendor with all the errors it is likely to ever have. These latent failures will manifest themselves whenever specific sets of instructions are executed. In this sense software failures are deterministic and not probabilistic. That is, identical code packages will fail at the same time, given identical inputs. However, because the location and number of faults present in the software is an unknown parameter, it is convenient to treat the failure process as a stocastic one with a constant (conservative assumption) or decreasing (realistic but a little more difficult to quantify) failure rate. Assuming that when a failure 
occurs, the software is fixed with reasonable effectiveness (i.e., fixing one fault introduces, on average, less than one new fault), then the reliability of the software will improve over time (hence the large number of reliability growth models discussed in the literature). The reliability of a software package will also depend on the effectiveness of the V\&V effort performed by the vendor. One measure of this effectivness is the coverage of the V\&V. Specifically, what percentage of all possible combinations of input parameters is actually tested in the V\&V. For smaller codes this could be $100 \%$, virtually assuring perfect operation of software. For larger packages, this number is likely much less than $100 \%$.

Software failures during operational use can be segregated into two categories: coding errors and inadequate desig. requirements. Coding errors comprise the majority of failures and are the subject of most studies and modeling efforts. However, failures can occur if inputs to the code fall outside the ranges assumed in the design specification. This type of situation is analogus to running a pump without cooling or lubrication oil. In a sense, most failures can be blamed on an inadequate design if you accept the premise that items are designed to not fail. Therefore if a failure occurs the design was by definition inadequate (i.e. the design should have included enough margin to overcome overly severe environments or manufacturing defect). However, failure rates generally are not segregated by root causes, and if the rates are calculated from actual operating histories, they will include the contribution from "inadequate" designs. For software there is the added complication for cases where failure rates are estimated using the results of the V\&V effort. Testing is likely performed using the ranges and combinations of input parameters that provided the basis for the design. In actual operation, it might be possible exceed or diverge from this set of expected inputs, resulting in possible failure of the program. In this case failure rates based on V\&V results might under-represent any contribution from exceeding the design basis.

The vendor is the only source of information that can be used to make accurate reliability estimates for a specific software package that has seen only limited operational use. This data can take the form of either the code 
parameters (e.g., lines of code, number of operations and operands, number of programmers that worked on the code, and others), or it can be the result of the developers' V\&V effort. V\&V data will be tabulated in the form of faults detected per unit of time for the debugging effort or a listing of each fault and the time since the previous one. ${ }^{10}$ The code parameter information is used in a deterministic calculation to estimate the fault density of the program, that is, the number of faults per line of code. This fault density wou?d in turn be required to be converted into an operating failure rate. The VaV type of data would be used in a reliability growth calculation to statisticaliy estimate the probability of the next failure.

Although software reliability data does exist, it is not readily accessible. The most desirable approach is to enlist the cooperation of the vendor in obtaining the data collected during their V\&V effort. "Generic" datasets froin V\&V efforts, do exist and can be purchased from the Data \& Analysis Center for Software ${ }^{f}$ (DACS). However, the data would still need to be analyzed using a reliability model such as those described in Reference 7 . Further, the DACS data was collected from Air Force programs and might not be directly applicable to commercial NPP applications. Given that the vendor is not willing to provide reliability data on their software, the likely approach for the PRA analysis will be to assume a failure probability distribution with limits generated from engineering judgement.

\subsection{HaRdware ReLiability}

While publicly available software failure data is limited, some information is available on the reliability of DCS hardware and on system performance. Since computers have been in use for years, a number of studies have been performed that examine system failures and their causes. ${ }^{11}$ However, these studies generally concentrate on root cause analyses and do not provide the information necessary to produce failure rates. In addition, it is

f. DACS is a Dept. of Defense Information Analysis Center operated by Kaman Sciences corporation. It is located in Utica, NY, the phone number is (315) 336-0937. 
sometimes difficult to discern the degree of similarity between the systems being studied and those used in NPP applications of DCSs. For example, one study $^{12}$ collected data and generated failure rates for Tandem computer systems. Applications of these systems include everything from gasoline pump controllers and automated teller machines to the New York Stock Exchange and an inventory database system for the U.S. Navy. This study segregated the data into three time periods and analyzed trends concerning failure causes. System performance improved from 8 years MTBF in 1985 to 21 years MTBF in 1989, with maintenance and hardware showing the largest improvement, and operations and software showing no improvement.

A source of failure rate information on electronic equipment is the Military Handbook - Reliability Prediction of Electronic Equipment, MIL-HDBK217F. ${ }^{13}$ Most of the information in this document addresses individual piece parts such as semiconductors (e.g., diodes and transistors), resistors, and capacitors. Information is also available on microcircuits and microprocessors.

One case study ${ }^{14}$ evaluated the reliability of an IBM mainframe computer. The study encompassed a 3-year period (January 1979 to December 1981), collected data on two IBM mainframes, and used information from an automatic error log maintained by the operating system. Only CPU errors occurring in the central processor and storage were included. The errors were classified as permanent (defined as the occurrence of a CPU machine-check condition at least four times in rapid succession) and temporary (defined as "not permanent"). The study documents a mean time between permanent errors of 289.8 hours based on 85 permanent errors (16.7\% of total errors).

Hardware failure data is collected and tracked by the DCS vendors. At the very least, they will have records on equipment performance during the warranty period (usually 12 to 18 months), namely, the number of items shipped to customers and the number of failed items returned. This information can be used to support a vendor's assertion that a proposed system will meet the reliability requirements specified by the customer. However, if a particular system is a prototype this process might not be straightforward. In these 
situations actual operating experience can be used only if individual components that have been used in past applications are also used in the prototype. This is the case for the Westinghouse Eagle-21 system, which shares a number of components with the Qualified Display Processing System (QDPS) installed at the South Texas plant. Table 1 presents the failure data collected from the South Texas QDPS to support Eagle-21 applications.

Table 1. Mean time between failure (MTBF) summary ${ }^{g}$ for DCS components in the South Texas Units 1 \& 2 Qualified Display Processing System (for period 8/87 to $11 / 90$ ).

\begin{tabular}{cccc}
\hline \hline Component & * of Failures & $\begin{array}{c}\text { Expected NTBF } \\
\text { (hr) }\end{array}$ & Actual NTBF (hr) \\
\hline Power Supplies & 27 & 60,000 & 57,554 \\
I/O Cards & 46 & 63,611 & 77,623 \\
Multibus Cards & 24 & 33,630 & 98,337 \\
Miscellaneous & 13 & 25,000 & 24,924 \\
\hline \hline
\end{tabular}

Some irformation is also available from the chemical process industry (CPI). Reference 15 documents a survey of CPI operating experience. The information is at the system and channel level, and although it does not identify the details of the system designs included in the compilation, it does provide data that can be used to generate dependent failure probabilities (i.e., beta factors). "able 2 lists the data extracted from Reference 15 and the resulting failure probabilities.

g. From presentation made by Westinghouse to the NRC Staff on November 26, 1991, on the proposed implementation of an Eagle-2I system at the Zion Nuclear Generating Station. 
Table 2. Sumr ary of failure data for redundant industrial computer systems.

\begin{tabular}{|c|c|c|c|c|c|c|c|}
\hline \multirow{2}{*}{$\begin{array}{c}\text { Total } \\
\text { operating } \\
\text { tive (system } \\
\text { years) }\end{array}$} & \multirow{2}{*}{$\begin{array}{l}\text { Nuber of } \\
\text { single } \\
\text { channel } \\
\text { failures }\end{array}$} & \multicolumn{6}{|c|}{ Mcaber of System (miltiple chanrel) Failures } \\
\hline & & $\begin{array}{l}\text { Failures } \\
\text { in comion } \\
\text { hardware }\end{array}$ & $\begin{array}{l}\text { Hardware } \\
\text { CCF }\end{array}$ & $\begin{array}{l}\text { Softmare } \\
\text { CCF }\end{array}$ & $\begin{array}{c}\text { Operat iona 1/ } \\
\text { ma intenance } \\
\text { CCF }\end{array}$ & $\begin{array}{l}\text { other } \\
\text { CCF }\end{array}$ & Total CCF \\
\hline 29.8 & 152 & 21 & 0 & 9 & 7 & 13 & 29 \\
\hline $\begin{array}{c}\text { hourly } \\
\text { failure rate }\end{array}$ & $5.8 E-4$ & 8. OE-5 & $1.9 \mathrm{E}-6$ & $3.5 E-5$ & $2.7 E-5$ & $5.0 E-5$ & $1.1 E-4$ \\
\hline $\begin{array}{c}\text { Dependent } \\
\text { failure } \\
\text { probability } \\
\text { (beta factor) }\end{array}$ & & N/A & 0.0033 & 0.059 & 0.046 & 0.079 & 0.19 \\
\hline $\begin{array}{l}\text { This } \\
\text { stanc } \\
* \quad \mathrm{Co}\end{array}$ & $\begin{array}{l}\text { ormat ion } \\
\text { redundant } \\
n \text { Cause } F\end{array}$ & $\begin{array}{l}\text { xtracte } \\
\text { tems fo } \\
\text { ire. }\end{array}$ & om Table & $\begin{array}{l}n \text { Refer } \\
\text { data } i\end{array}$ & $\begin{array}{l}15 \text { and inclu } \\
\text { a ilable. }\end{array}$ & inly th & $1-01$ \\
\hline
\end{tabular}

Reference 15 also lists information on the individual components that compose a DCS. Again, the source of the data is the CPI. Two types of information were available: field data and analytical data. As the name suggests, the field data were collected from actual DCS operating experience. The analytical data were the result of detailed DCS reliability models using the techniques and information found in MIL-HDBK-217. Table 3 contains a summary of the component independent-failure rate information presented in Reference 15 along with statistics that result from combining the individual rates to generate "generic" averages. 
Table 3. Failure rate estimates for DCS components. [Ref. 15]

\begin{tabular}{|c|c|c|c|c|c|}
\hline DCS Component & $\begin{array}{l}\text { Fallure } \\
\text { rate } \\
\text { estimate } \\
(/ y r) \\
\end{array}$ & $\begin{array}{l}\text { Data } \\
\text { source }\end{array}$ & $\begin{array}{l}\text { Basis of } \\
\text { failure } \\
\text { rate } \\
\text { est imate } \\
\end{array}$ & $\begin{array}{l}\text { Mean } \\
(/ y r)\end{array}$ & $\begin{array}{l}\text { Standard } \\
\text { deviation } \\
\text { (/yr) }\end{array}$ \\
\hline \multirow[t]{4}{*}{ Processor (CPU/memory) } & 0.45 & OREDA & field data & 0.74 & 0.6 \\
\hline & 1.8 & HED & field data & & \\
\hline & 0.33 & Triconex & analytical & & \\
\hline & 1.3 & HED & analytical & & \\
\hline \multirow{4}{*}{ Digital input cards } & 0.071 & HED & field data & 0.079 & 0.043 \\
\hline & 0.096 & HED & analytical & & \\
\hline & 0.0073 & OREDA & field data & & \\
\hline & 0.086 & Triconex & analytical & & \\
\hline \multirow[t]{2}{*}{ Digital output cards } & 0.072 & OREDA & field data & & \\
\hline & 0.040 & Triconex & analytical & & \\
\hline Ana log input card & 0.11 & Triconex & analytical & & \\
\hline Ana log input/output card & 0.15 & Triconex & ana lyt iczl & & \\
\hline \multirow[t]{4}{*}{ Power supply } & 0.25 & OREDA & field data & 0.26 & 0.18 \\
\hline & 0.14 & H\&O & field data & & \\
\hline & 0.14 & Triconex & analy=ical & & \\
\hline & 0.52 & HED & ana lytical & & \\
\hline
\end{tabular}

Notes:

OREDA OREDA, Offshore Reliability Data Handbook, OREDA Participants, PO Box 370, N-1322 HOVIK, Norway, 1984.

H\&D M. Humphreys \& B. K. Daniels, "How Do Electronic System Fa: lure Rate Predictions Compare with Field Experience? SRS/GR/58, Systems Reliability Service, United Kingdom Atomic Energy Authority, Culcheth, Warrington, WA3 4NE., UK, October 1982.

Triconex TRICON Reliability Analysis, Triconex Corporation, Irvine, CA.

Although the best source of failure rate information for a specific application is the system vendor, generic data is avaijable for DCS components. This information represents a wide range of applications including offshore oil drilling platforms and chemical process industries. In addition most of the information is at least 10 years old. Therefore, the application of these failure rates to current commercial NPP DCSs must be done with some caution. 


\section{PRA MODELING OF DCS}

\subsection{INTRODUCTION}

To model any system, including safe-grade computerized control systems, requires a detailed understarding of both the system configuration and its operation. The first s:ep in constructing a model is to clearly identify the system boundaries and those elements that perform the essential functions of the system to be modeled. Therefore, before detailed modeling of the DCS can begin, the plant-specific information listed below is required:

1. Procedures

a. Emergency and Abnnrmal orocedures.

b. Surveillance procedures for:

- I\&C components of interest (i.e., controllers, CPUs, power supplies, iogic cards, and cables;

- Specific hardware of interest (i.e., pumps, valves, and piping).

c. Maintenance procedures for:

- I\&C components of interest;

- Specific hardware of interest.

2. Logic and block diagrams for:

a. "New" DCS including connections to other plant systems.

b. "01d" analog system.

3. Piping and instrumentation diagrams for components and instruments connected to and controlled by the DCS.

4. Vendor suppiied information on the DCS.

5. Technical specifications.

6. NRC licensing information on the DCS modification

a. Request for change to technical specifications.

b. Response from NRC.

7. Any reliability or failure information gathered by the plarit or vendor

a. Software.

b. Hardware. 
The common practice in modeling the existing safety-grade analog control systems in PRAs is not to model them explicitly. ${ }^{16,17,18}$ Analog control and actuation systems in safety-critical applications are designed to be failsafe. This means anticipated faults result in the system being in its most desired state with respect to $\mathrm{plant}$ safety. For example, in a safety feature actuation system, likely failures produce a safety actuation signal. (The system is maintained in a normally energized state, with the actuation signal generated by deenergizing relays.) Furthermore, these systems are usually configured with redundant channels such that at least two channels are required to fail before the system function fails. Even if an actuation function were to fail, recovery would likely be possible via manual actuation from the control room. For these reasons, safety-grade analog trip and actuation systems are deemed to be unlikely sources of system failures in PRAs and are not normally modeled explicitily.

Before a DCS can be modeled explicitly, the specific mission requirements (or system failure modes) need to be identified. For example, does the system perform a one-time actuation function, or does it provide a continuous control function? This determines whether the system should be modeled as a per-demand probability or as an unavailability over a specified time. This is particularly applicable to hardware failures, for once a circuit board is operating, signal processing would appear to have little influence on the likelihood of that board failing, and its failure can be modeled as a random process. However, different signals and processes do exercise different portions of the software. Tnerefore, even if a system is operating and undergoing continuous error checking, it appears reasonable to postulate a per-demand failure model for the software, given the presence of a new signal being processed by the system. Another aspect that needs to be considered is that of system testing. Most DCSs incorporate some type of periodic or continuous testing. Therefore, if or when a failure occurs the system will likely be quickly repaired. The consequence of this is that it might be safe to assume the system is fully operational at the beginning of its designated mission. 
One issue that has not been explored very much in the literature is that of external hazards resulting in a failure of a DCS. This includes not only fires, water intrusion, earthquakes, and physical attack (e.g., running into a cabinet with a fork-lift) but also less severe environmental conditions such as high temperature or humidity and electromagnetic and radio frequency interference. However, given that the DCS installation is done in conformance with the many codes and standards in existence ${ }^{19}$ these issues are not 1 ikely to be a concern. Nevertheless, external hazards will be considered in the DCS PRA.

\subsection{Outline of Analysis Plan}

An assessment of the risk impact of an advanced teshnology system on a plant-specific model will likely examine the effect of an Eagle-21. or EFIC-1ike system on a Westinghouse or B\&W plant. A two-step process will be employed in which the existing PRA model will be modified to explicitly incorporate first the old analog system then the new DCS. Explicitly modeling the old analog system is needed in order to rebaseline the PRA both quantitatively and qualitatively. The second step will be to replace the analog system model with a DCS model in the PRA and quantify it. In this way the comparison between the analog and digital systems will be straightforward and can be made on both a qualitative and quantitative basis.

Figure 1 is a simplified flow diagram of one channel of an Eagle-21 system. The figure depicts the three subsystems composing the channel, and identifies the input and output signals received and generated by the channel. Depending on the particular function of interest, a specific signal path would pass through five separate modules. These would be modeled as a series process (i.e., any one can fail the channel), with each module being prone to both hardware and software faults. Failure of the card chassis (which would include the fan and signal buses) and the power supply would also be modeled. In addition, common cause failures and any potential single failure points would be included. This model would take the form of a fault tree that accounts for the fault tolerance of the system design, that is, whether it is a 2-out-of-4 success criterion or something else. Figure 2 is one simple 
example of the top logic for a DCS with 2-out-of-4 logic. Whether the system operates using identical software in all channels or diverse software in each channel, determines where the software is modeled in the fault tree. If identical software is used, software faults would appear under the common cause event. If diverse software is used, they would appear under the individual channel failure events. Because of the self diagnostics, continuous testing, and relative ease of repair of CCSs, latent faults and unavailability caused by test or maintenance will probably not be modeled (unless information to the contrary can be found, e.g., long mean time to repair).

The failure rates used to quantify the DCS model will iikely be those presented in Tables 2 and 3 . Table 3 contains independent failure rates for the individual components in a DCS channel and Table 2 has conditional failure probabilities for common cause failures. For software, the most acurate source of failure information is the vendor. As discussed in section 4.1, many factors influence the reliability of a particular software package, for example: size of the code, programing environment, V\&V effort and, amount of operational use. The vendor should be the best source of information, if not on failure rates themselves then for the data needed to generate failure rates. Another source of information might be the user (i.e., licensee), depending on the amount of experience they have had with the code and the comprehensiveness of their data collection. The type and quality of information available from these sources will determine the model used to estimate software failure rates, be it a deterministic model, a reliability growth model, or something else. As a last resort, failure rates will be generated from engineering judgment utilizing estimates found in the literature and described previously. This will likely take the form of a lognormal distribution with $90 \%$ uncertainty bounds of $1 E-4$ and 0.1 (per demand). 


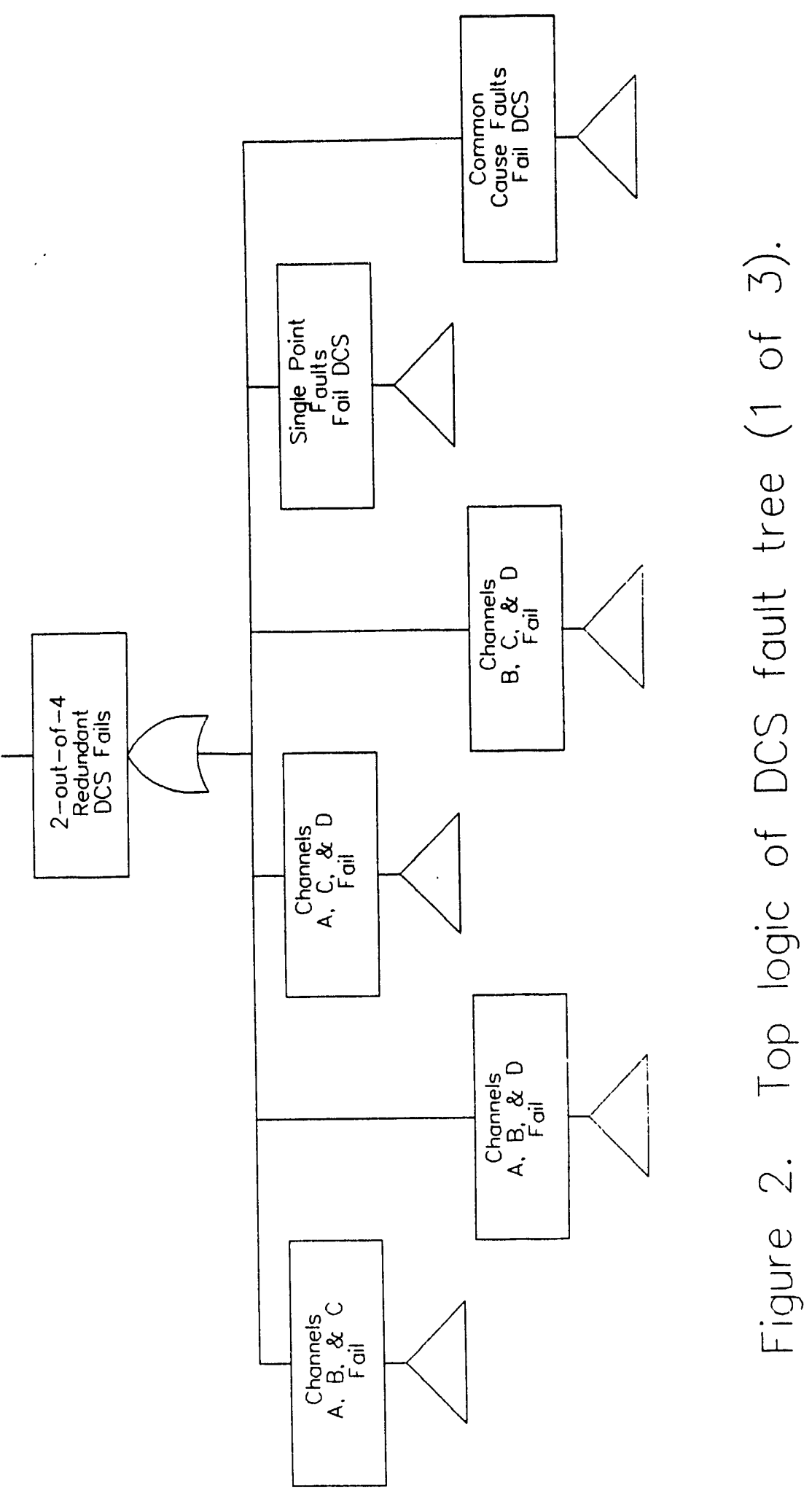

Figure 2. Top logic of DCS fault tree (sheet 1 of 3 ). 


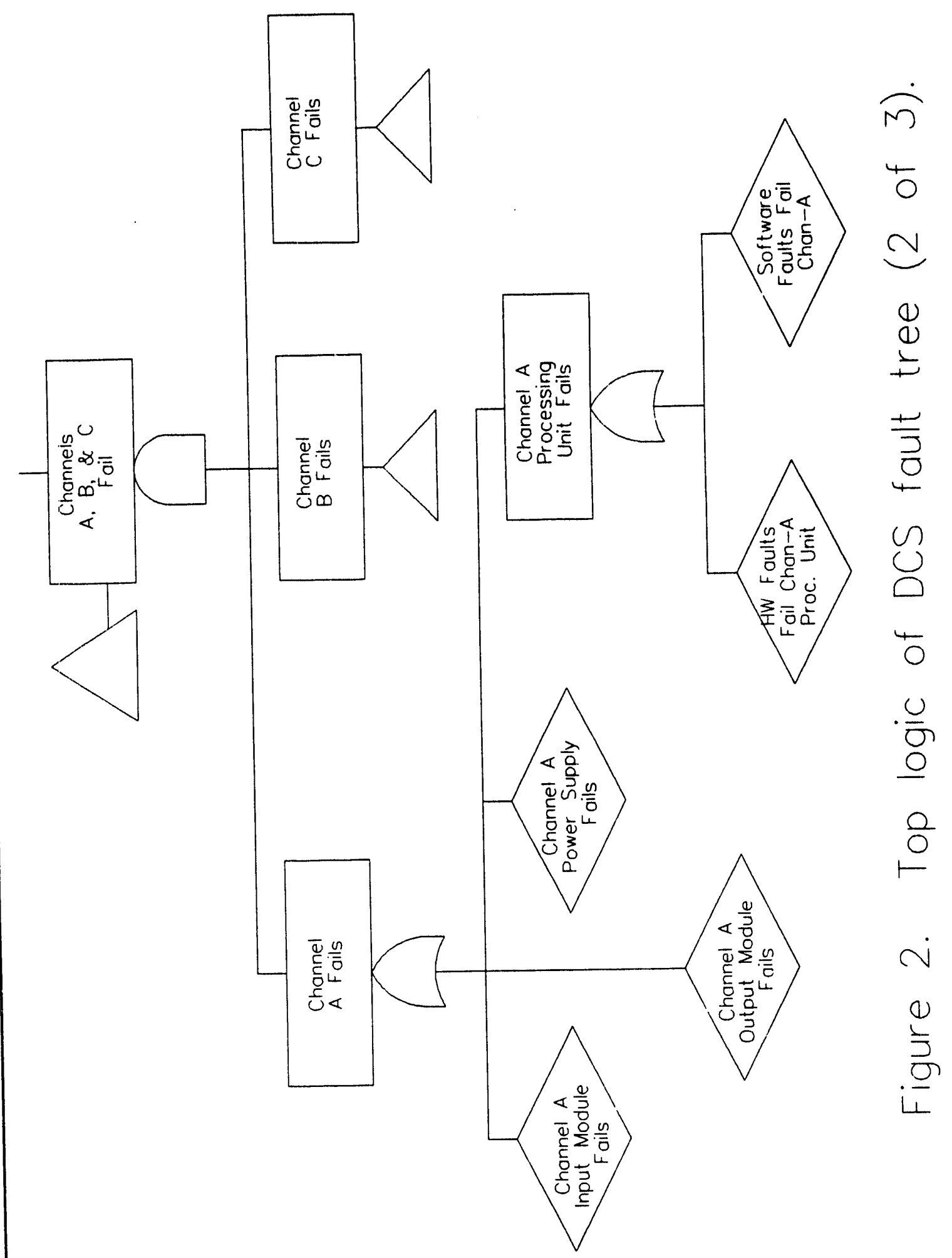

Figure 2. Top logic of DCS fault tree (sheet 2 of 3 ). 


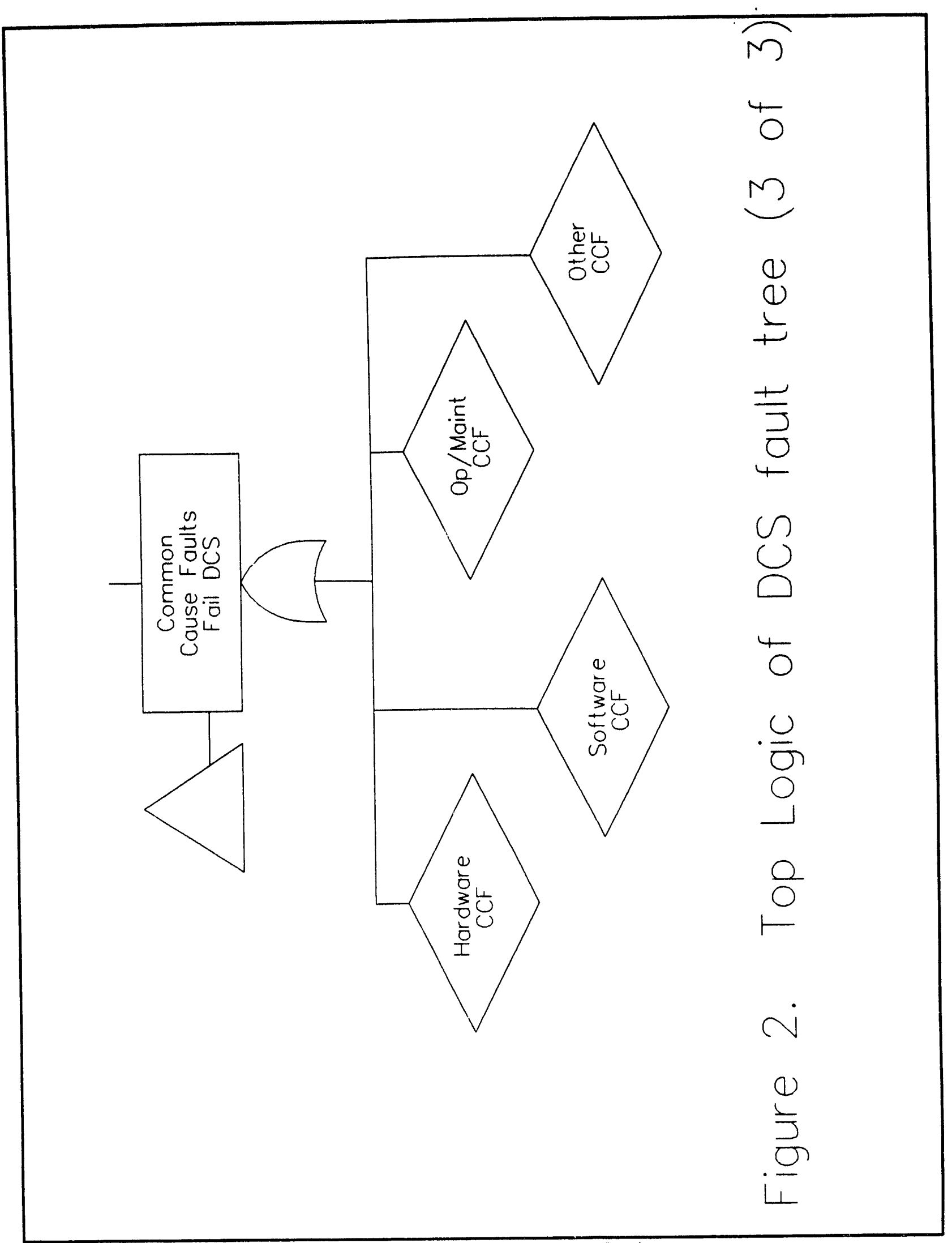

Figure 2. Top logic of DCS fault tree (sheet 3 of 3 ). 


\section{SUMMARY}

Digital control systems are being implemented in more and more NPPs. The primary motivation behind this process is the obsolescence of the existing analog systems. Although the digital systems often offer much more capability than the analog systems they replace, their use appears to be limited to a like-for-like ${ }^{20}$ replacement. Information on both computer hardware and software failures is very limited; vendors are not willing to advertise failures of their systems. Chemical process industry experience is a source for some computer hardware failure data. Published literature on software reliability deals overwhelmingly with methods for assessing software reliability and very little on actual failure rates. What little is available is mostly expert opinions. However, the information that is available can be used to postulate upper and lower limits on possible failure rates for both hardware and software. Because of the fail-safe nature and redundancy in the design of the old analog systems, they have been judged to be insignificant contributors to risk and are typically not modeled in detail in PRAs. Whether or not this characterization holds true for the newer DCSs will be tested through the use of a limited PRA analysis currently planned for Fall 1993. 


\section{REFERENCES}

1. U.K. AEA Technology, SRD, Software Tools Available at SRD, SRD/TDP/MAL/07, Issue 1.1, September 1990.

2. R. J. Burroni et al., "Digital Control Systems in Nuclear Power Plants Recent Applications Experience," Proceedings: Advanced Digital Computers, Controls, and Automation Technologies for Power Plants, EPRI TR-100804, August 1992.

3. R. A. Kisner and R. E. Battle, Fault-Tolerant Architecture: Evaluation Methodology, EPRI Report TR-100803, August 1992.

4. Connecticut Yankee - PDCR (P1ant Design Change or Revision) No.: 1127, Rev. 0, Title: Auxiliary Feedwater Modifications, Received from M. H. Brothers, November 18, 1992.

5. R. L. Dungan and M. T. Amick, "B\&W PWR Advanced Control System Hardware Development," Proceedings: Advanced Digital Computers, Controls, and Automated Technologies for Power P7ants, EPRI TR-100804, August 1992, p.21-1.

6. R. W. Winks, T. L. Wilson and M. Amick, "B\&W PWR Advanced Control System Algorithm Development, " Proceedings: Advanced Digital Computers, Controls, and Automated Technologies for Power Plants, EPRI TR-100804, August 1992, p. 22-1.

7. H. Pham and M. Pham, Software Reliability Models for Critical Applications, EGG-2663, December 1991.

8. Bev Littlewood and Lorenzo Strigini, "The Risks of Software," Scientific American, November 1992, p.62.

9. J. C. Laprie and B. Littlewood, "VIEWPOINT - Probabilistic Assessment of Safety-Critical Software: Why and How?," Communications of the ACM, 35, 2, February 1992.

10. C. J. Mueller ed., Quantitative Software Reliability Analysis of Computer Codes Relevant to Nuclear Safety, NUREG/CR-2186, December 1981.

11. R. Chillarege and D. P. Siewiorek, ed., "Special Issue - Experimental Evaluation of Computer Systems Reliability, "IEEE Transactions on Reliability, 39, 4, October 1990, pp. 403-510.

12. J. Gray, "A Census of Tandem System Availability Between 1985 and 1990," IEEE Transactions on Reliability, 39, 4, October 1990, pp. 409-418.

13. Military Handbook - Reliability Prediction of Electronic Equipment, MILHDBK-217F, December 2, 1991. 
14. R. K. Iyer and M. C. Hsueh, "Analys is of Field Data on Computer Failures," J. of Comput. Sci. \& Technol., 5, 2, 1990.

15. H. M. Paula, MW. Roberts and R. E. Battle, "Operational Failure Experience of Fault-Tolerant Digital Control Systems," Reliability Engineering and System Safety, 39, 3, 1993, pp.273-289.

16. R. C. Bertucio and J. A. Julius, Analysis of Core Damage Frequency: Surry, Unit 1 Internal Events, NUREG/CR-4550, Vo1.3, Rev.1, Apri1 1990.

17. A. M. Kolaczkowski et al., Analysis of Core Damage Frequency: Peach Bottom, Unit 2 Internal Events, NUREG/CR-4550, Vo1.4, Rev.1, August 1989.

18. M. T. Drouin et al., Analysis of Core Damage Frequency: Grand Gulf, Unit 1 Internal Events, NUREG/CR-4550, Vol.6, Rev.1, September 1989.

19. Letter from T. J. Kenyon, U.S. NRC/NRR to N. J. Liparulo, West inghouse Electric Corporation, "Request for Additional Information on the AP600," Docket No. 52-003, March 12, 1993.

20. R. J. Carter and R. E. UTrig, Human Factors Issues Associated with Advanced Instrumentation and Controls Technologies in Nuclear Plants, NUREG/CR-5439, June 1990. 


\section{APPEndiX A \\ Westinghouse Process Protection System History}

Process Protection Systems in Westinghouse plants comprise three generations of analog electronics: Foxboro H-Line, Westinghouse 7100 Series, and Westinghouse 7300 Series. The Foxboro H-Line represents the first generation of analog process protection equipment, was manufactured during the 1965 to 1972 period, and was used in 25 NPPs. The second generation of equipment is the Westinghouse 7100 series. This series was manufactured during the 1970 to 1973 period, and was installed in 13 NPPs. Westinghouse 7300 Series is the third generation, was manufactured during the 1973 to 1983 period, and was installed in 44 NPPs. Table A-1 summarizes some of the experience the U.S. NPP industry has had with retrofitting the Eagle-21 system.

Table A-1. U.S. NPP experience with the Eagle-21 system.

\begin{tabular}{llll}
\hline Plant & $\begin{array}{l}\text { Year Eagle-21 } \\
\text { installed }\end{array}$ & System replaced & Notes \\
\hline Zion 182 & 1992 & 7100 Series & $\begin{array}{l}\text { No functional } \\
\text { upgrades }\end{array}$ \\
Sequoyah 182 & 1990 & Foxboro H-Line & $\begin{array}{l}\text { Included changes } \\
\text { to RPS logic }\end{array}$ \\
$\begin{array}{l}\text { Turkey Point 3\&4 } \\
\text { Watts Bar 1 }\end{array}$ & 1989 & $\begin{array}{l}7300 \text { Series } 14 \\
\text { racks, hot leg T Tave }\end{array}$ & $\begin{array}{l}\text { Supported RTD } \\
\text { bypass elimination }\end{array}$ \\
$\begin{array}{l}\text { Diablo Canyon } \\
\text { 182 }\end{array}$ & In-progress & & \\
\hline \hline
\end{tabular}




\section{APPENDIX B \\ Canadian DCS Experience}

The following is based on a discussion with Ontario Hydro staff $(2 / 11 / 93$ conference call with INEL personnel and David Beattie, Ed Fenton, Brian Howard, and Rick Holendorf of Ontario Hydro) on their experience with Digital Control Systems (DCS). Ontario Hydro operates three nuclear power plant sites, and these are: Pickering, an eight-unit site of 515 and 516 MWe CANDU plants (pressurized heavy water-moderated reactors) that went into commercial operation in 1971-1973 (Units 1-4) and 1983-1986 (Units 5-8); Bruce, an eightunit site of 848 and 860 MWe plants; and Darlington, a four-unit site of 881 MWe units, where Unit-2 went commercial in 1990 and Units 1, 3, and 4 are projected to be commercial in 1992-1993.

The discussions only referred to the Pickering site, as an example of where DCS has been retrofit into a plant, and the Darlington site, where DCS is part of the original design. For all Ontario Hydro plants, the utility is the principal Architect/Engineer and also the Constructor.

The Ontario Hydro practice has been to develop a number of computerized control systems. These include a plant process control system, an on-line refueling computer, and shutdown (reactor trip) computers. The on-line refueling process computer is almost completely decoupled from all other plant operations. The plant process control system is a dual redundant system used to control the normal day-to-day operations of the unit. It is not a safety system and was designed with an availability goal of 99.95 to $99.99 \%$. It also includes a plant display system for the operator interface.

The shutdown system (SDS) consists of three levels of redundancy. First, there are two independent subsystems. Shutdown subsystem \#1 inserts the control rods into the reactor core. Shutdown subsystem \#2 injects a liquid poison into the coolant system, which is capable of rendering the reactor subcritical without inserting the control rods. The second level of redundancy resides in each subsystem, which comprises triplicated hardware and 
2-out-of-3 channel voting. The final level of redundancy is the actuation of each channel by any one of two or more parameters (e.g., reactor coolant level or pressure).

The reliability of the SDS was prescribed during the development of the probabilistic risk assessment (PRA) of the Darlington plant. In this effort reliability targets were assigned to the various components of the PRA and then each piece was verified against its target. For the SDS, a reliability target of about $10^{-6}$ per demand was assigned. Each of the two redundant subsystems was then assigned a reliability of $10^{-4}$ per demand, which was then verified through a testing program.

A couple of final points were made concerning software reliability. Typically, Ontario Hydro develops their own software. The documentation of this process is performed by the quality assurance (QA) program, which consists of the following:

1. Partitioning the system function into functional modules,

2. Developing a requirements document (this includes quality engineering),

3. Developing a design description from the requirements document,

4. Documenting a plan for implementing the design requirements, and

5. A verification plan.

Finally, the safety importance and reliability of the system is described in a safety report.

The Ontario Hydro staff had two further comments concerning software reliability. Based on their experience, a program module containing more than 5,000 lines of code was too big to allow its reliability to be demonstrated, and 100,000 lines was too big to assure quality. On a qualitative basis, discussions with Ontario Hydro personnel generated the following list of questions that can provide insight for assessing the quality of a software package.

1. How frequently does the system need to be rebooted?

2. How difficult is it to get the system back up and running after it has gone down? 
3. How complicated are the instructions to reboot the system?

4. How adequate is the vendor support for the DCS (i.e., availability, response time, and accuracy) hardware, and software?

5. How is the vendor support obtained (i.e., telephone, area representative, or on-site support)?

6. How does the vendor rectify "bugs" or failures of the software (e.g., software patch or new version)?

7. How many software patches or versions of the software have been needed or supplied since the system was first operated?

8. Does the vendor supply information bulletins concerning software/hardware problems with the DCS?

9. How is the configuration control of the software handled?

10. Is the system more reliable now compared with when it was first installed? 


\section{APPENDIX C BIBLIOGRAPHY}

1. Mourad, S. and Andrews, D., "Ccncise Papers on the Reliability of the IBM MVS/XA Operating System," IEEE Transactions on Software Engineering, Vol. SE-13, No. 10, October 1987.

2. Malaiya, Y.K., N. Karunanithi and P. Verma, "Predictability of SoftwareReliability Models," IEEE Transactions on Reliability, Vol. 41, No. 4, December 1992.

3. Kenyon, T.J., NRC, to N. J. Liparulo, Westinghouse, Subject: "Request for Additional Information on the Westinghouse AP600 Design," March 1993.

4. Laprie, J.C., "Hardware-and-Software Dependability Evaluation," Information Processing, 1989.

5. Ichiyen, N. and Joannou, P., "The CANDU Approach to Digital Safety Systems," Nuclear Engineering Internationa1, Vo1. 36, No. 446, September 1991.

6. Fryer, M.0., "Risk Assessment of Computer Controlled Systems, " IEEE Transactiolis on Software Engineering, Vol. SE-11, Vo. 1, January 1985.

7. Currit, P.A., Dryer. M. and Mills, H.D., "Certifying the Reliability of Software," IEEE Transactions on Software Engineering, Vol. SE-12, No. 1, January 1986.

8. Rennels, D.A., "Fault-Tolerant Computing - Concepts and Examples," IEEE Transactions on Computers, Vo1. C-332, No. 12, December 1984.

9. Chenoweth, H.B., "Reliability Prediction, in the Conceptual Phase, of a Processor System With Its Embedded Software," Annual Reliability and Maintainability Symposium, 1991.

10. Bastos Martini, M.R., Kanoun, K. and Moreira de Souza, J., "SoftwareReliability Evaluation of the TROPICO-R Switching System," IEEE Transactions on Reliability, Vol. 39, No. 3, August 1990.

11. Miller, D.R., "Exponeniial Order Statistic Models of S',ftware Reliability Growth," IEEE Transactions on Software Engineering, Vo.. SE-12, No. 1, January 1986.

12. Iyer, R.K. and Rossetti, D.J., "Effect of System Workload on Operating System Reliability: A Study on IBM 3081," IEEE Transaci :uns on Software Engineering, Vol. SE-11, No. 12, December 1985.

13. Okumoto, K., "A Statistical Method for Software quality Control," IEEE Transactions on Software Engineering, Vol. SE-11, No. i2, December 1985. 
14. Shen, V.Y., Yu, T. and Thebaut, S.M., "Identifying Error-Prone Software An Empirical Study," IEEE Transactions on Software Engineering, Vol. SE-11, No. 4, April 1985.

15. Westgate, C.J., "Validation of an Exponentially Decreasing Failure Rate Software Reliability Model Thesis, "Air Force Institute of Technology, 1989.

16. Hecht, H. and Hecht, M., "Software Reliability in the System Context," IEEE Transactions on Software Engineering, Vol. SE-12, No. 1, January 1986.

17. Troy, R. and Moawad, R., "Assessment of Software Raliability Models, "IEEE Transactions on Software Engineering, Vo1. SE-11, No. 9, September 1985.

18. Scholz, R.-W., "Software Reliability Modeling and Analysis," IEEE Transactions on Software Engineering, Vol. SE-12, No. 1, January 1986.

19. Anderson, T., Barrett, P.A., Halliwell, D.N. and Moulding, M.R., "Software Fault Tolerance: An Evaluation," IEEE Transactions on Software Engineering, Vol. SE-11, No. 12, December 1985.

20. McAllister, D.F. and Vouk, M.A., "Experiments in Fault Tolerant Software Reliability," North Carolina State University, April 1989.

21. Thomasian, A. and Bay, P.F.: "Integrated Performance Models for Distributed Processing in Computer Communication Networks, "IEEE Transactions on Software Engineering, Vol. SE-11, No. 10, October 1985.

22. Panzieri, F. and Rande11, B., "Interfacing UNIX to Date Communications Networks," IEEE Transactions on Software Engineering, Vo1. SE-11, No. 10, October 1985.

23. Vouk, M.A. and McAllister, D.F., "Multi-Version Software Reliability Through Fault-Avoidance and Fault-Tolerance," National Aeronautics and Space Administration, September 1989.

24. Yamada, S. and Osaki, S., "Software Reliability Growth Hodeling: Models and Applications," IEEE Transactions on Software Engineering, Vol. SE-11, No. 12, December 1985.

25. Dunham, J.R., "Experiments in Software Reliability: Life-Critical Applications," IEEE Transactions on Software Ergineering, Vol. SE-12, No. 1, January 1986.

26. Sofer, A. and Miller, D.R., "A Nonparametric Software - Reliability Growth Mode1," IEEE Transactions on Software Engineering, Vo1. 40, No. 3, August 1991 .

27. Casti110, X., "A Compatible Hardware/Software Reliability Prediction Model, "Department of Computer Science, Carnegie-Mellon University, July 1961 . 
28. Downs, T. and Garrone, P., "Some New Models of Software Testing with Performance Comparisons," IEEE Transactions on Reliability, Vol. 40, No. 3, August 1991.

29. Keene, S.J., "Cost Effective Software Quality," Annual Reliability and Maintainability Symposium, 1991.

30. Belli, F. and Jedrzejowicz, P., "Fault-Tolerant Programs and Their Reliability," IEEE Transactions on Reliability, Vol. 39, No. 2, June 1990.

31. Cseniki, A., "Bayes Predictive Analysis of a Fundamental Software Reliability Model," IEEE Transactions on Reliability, Vol. 39, No. 2, June 1990.

32. Sandoh, H. and Sawada, K., "Reliability Demonstration Testing for Discrete-Type Software Products," Annual Reliability and Maintainability Symposium, 1991.

33. "Why Power Computing Company for Your Software QH. Needs?" Power Computing Company.

34. "Standard for a Software Quality Metrics Methodology," Draft, Institute of Electrical and Electronic Engineers, Inc., April 1990.

35. "Reliability Prediction of Electronic Equipment," Military Handbook, January 1990.

36. Littlewood, B., "Limits to Evaluation of Software Dependability," Centre for Software Reliability Conference, September 1990.

37. Downs, T. and Scott, A., "Evaluating the Performance of SoftwareReliability Models," IEEE Transactions on Reliabilitiy, Vol. 41, No. 4, December 1992.

38. Laprie, J.C. and Littlewood, B., "Probabilistic Assessment of SafetyCritical Software: Why and How?" Communications of the ACM, Vol. 35, No. 2, February 1992.

39. Iyer, R.K. and Hsueh, M.-C., "Analys is of Field Data on Computer Failures," Journal of Computer Science \& Technology, Vol. 5, No. 2, 1990.

40. Protzei, P.W., Palumbo, D.L. and Arras, M.K., "Performance and FaultTolerance of Neural Networks for Optimization," NASA Contractor Report 187582, ICASE Report No. 91-45, June 1991.

41. Coffin, R.T., McLean, J.R., Raby, C.L. and Sullivan, J.W., "Enhanced Collection and Recording of Computer System Hardware/Software Event Trace Data and System Error Data, "IBM Technical Disclosure Bulletin, Vol. 27, No. 8, January 1985.

42. "Computer Failure Data," prepared by Project Sete, New York University School of Engineering and Science, May 1969. 
43. Protze1, P.W., Palumbo, D.L. and Arras, M.K., "Performance and FaultTolerance of Neural Networks for Optimization Final Report, " Institute for Computer Applications in Science and Enginee:ring, June 1991.

44. DOE Office of Nuclear Safety, "Temporary Loss of Four Group 1 Instruments Due to Improper Programming of a DCS," Operating Experience Weekly Summary, December 4 - December 10, 1992, Summary 92-33.

45. Deleted.

46. Beltrachi, L. and Hecht, H., "Qualification Testing of Class IE Software."

47. Dartt, S.R., "A Survey of Distributed Control Systems," INTECH, September 1989.

48. Dah11, G., "Software Safety Checks Using Storea Tested Paths," SAFECOMP symposium, November 1991.

49. Laprie, J.C. and Kanoun, K., "X-Ware Reliability and Availability Modeling," IEEE Transactions on Software Engineering, Vol. 189, No. 2, February 1992.

50. Pfleeger, S.L., "Measuring Software Reliability," IEEE Spectrum, August 1992.

51. Noon, D.W., "Practical Software Reliability," The Foxboro Company.

52. Stubler, H.J. and Weber, W., "Failure Rate of Process Computers," IFAC Automation for Mineral Resource Development, 1925.

53. Voas, J., More11, L. and Miller, K., "Predicting Where Faults Can Hide from Testing," IEEE Software, March 1991.

54. Paula, H.M., Roberts, M.W. and Battle, R.E., "Operational Failure Experience of Fault-Tolerant Digital Control Systems, "Reliability Engineering and System Safety, Vol. 39, 1993.

55. Paula, H.M. and Roberts, M.W., "Reliability Performance of Fault-Tolerant Digital Control Systems," Plant/Operations Progress, Vol. 10, No. 2, April 1991.

56. Littlewood, B. and Strigini, L., "The Risks of Software," Scientific American, November 1992.

57. Dugan, J.B., Bavuso, S.J. and Boyd, M.A., "Fault Trees and Markov Models for Reliability Analysis of Fault-Tolerant Ligital Systems, "Reliability Engineering and System Safety, Vo1. 39, 1993.

58. Paula, H.M., "Failure Rates for Programmable Logic Controllers," Reliability Engineering and System Safety, Vol. 39, 1993. 
59. "Proceedings: Advanced Digital Computers, Controls, and Automation Technologies for Power Plants," EPRI TR-100804, Project 3208, August 1992.

60. "IEEE Transactions on Reliability," Vol. 39, No. 4, October 1990.

61. "Reliability Engineering and System Safety," Special Issue, Vo1. 39, No. 3, 1993.

62. Belli, F. and Jedrzejowicz, P., "Fault-Tolerant Prograns and Their Reliability," IEEE Transactions on Reliability, Vol., 39, No. 2, June 1990.

63. Sofer, A. and Miller, D.R., "A Nonparametric Software-Reliability Growth Model," IEEE Transactions on Reliability, Vol., 40, No. 3, August 1991.

64. Sandoh, H., "Reliability Demonstration Testing for Software," IEEE Transactions on Reliability, Vol., 40, No. 1, April 199i.

65. Butler, R. and Finelli, G.B., "The Infeasibility of Experimental Quantification of Life-Critical Software Reliabiiity," ACM SIGSOFT -91 Conference, New Orleans, December 4-6, 1991.

66. "Testing and Installation of a BWR Digital Fee:water Control System," EPRI NP-5524, Project 2448-5, December 1987.

67. Komoriya, H., Mueller, C.J. and Morris, E.E., "Quantitative Software Reliability in Nuclear Safety," CONF-8110266--i.

68. Mueller, C.J., Komoriya, H., Meek, C.C., Morris, E.E. and Vesely, W.E., "Quantitative Software Reliability Analys is of Computer Codes Relevant to Nuclear Safety," NUREG/CR-2186, December 1981.

69. Kisner, R.A., Battle, R.E. and Kisner, R.A., "Fauit-Tolerant Architecture: Evaluation Methodology," TR-100803, Project 3008-1, August 1992.

70. "Reliability Prediction of Electronic Equipment," Military Handbook, MILHDBK-217F, December 1991.

71. "Software Tools Available at SRD," AEA Technologv, September 1990.

72. Swern, F.L., "Hardware and Software Reliability Estimation Using Simulations," Final Report, Stevens Institute of Technology, Grant NAG-1587, June 1990.

73. "Safety Implications of Computerized Process Cor.tro? in Nuclear Power Plants," IAEA Technical Committee Meeting, Vie!nna, November 13-17, 1989.

74. "Reliability Analysis of a Fault-Tolerant Gas Turbine Control System," Final Report, EPRI AP-5425, Project 2101-7, Serternber 1987.

75. "Gas Turbine Control System Retrofit, Volume 2: Georgia Power Control Improvements," EPRI AP-3875, Volume 2, Project 2101-7, September 1991. 
76. Nolan, A.E., "SoHar Inc. Review: Qualified Display Processing System (QDPS) South Texas Project, Units 1 and 2," Technical Evaluation Report, EGG-NTA-7786, July 1987.

77. Miller, L.A., Groundwater, E. and Mirsky, S.M., "Survey and Assessment of Conventional Software Verification and Validation Methods, "Final, USNRC, December 1992.

78. Stacey, B.J., "Software Quality Engineering: A Practical Approach," Presentation at INEL.

79. Pham, H. and Pham, M., "Software Reliability for Critical Applications," EGG-2663, December 1991.

80. "Proceedings: 1985 Seminar on Power Plant Digital Control and FaultTolerant Microcomputers," EPRI NP-4769-SR, September 1986.

81. "Proceedings: Methodologies, Tools, and Standards for Cost-Effective, Reliable Software Verification and Validation, "ERI TR-100294, January 1992.

82. Sumito, U. and Masuda, Y., "Analys is of Software Ava: ability/Reliability Under the Influence of Hardware Failures," IEEE Trarsactions on Software Engineering, Vol. SE-12, No. 1, January 1986. 

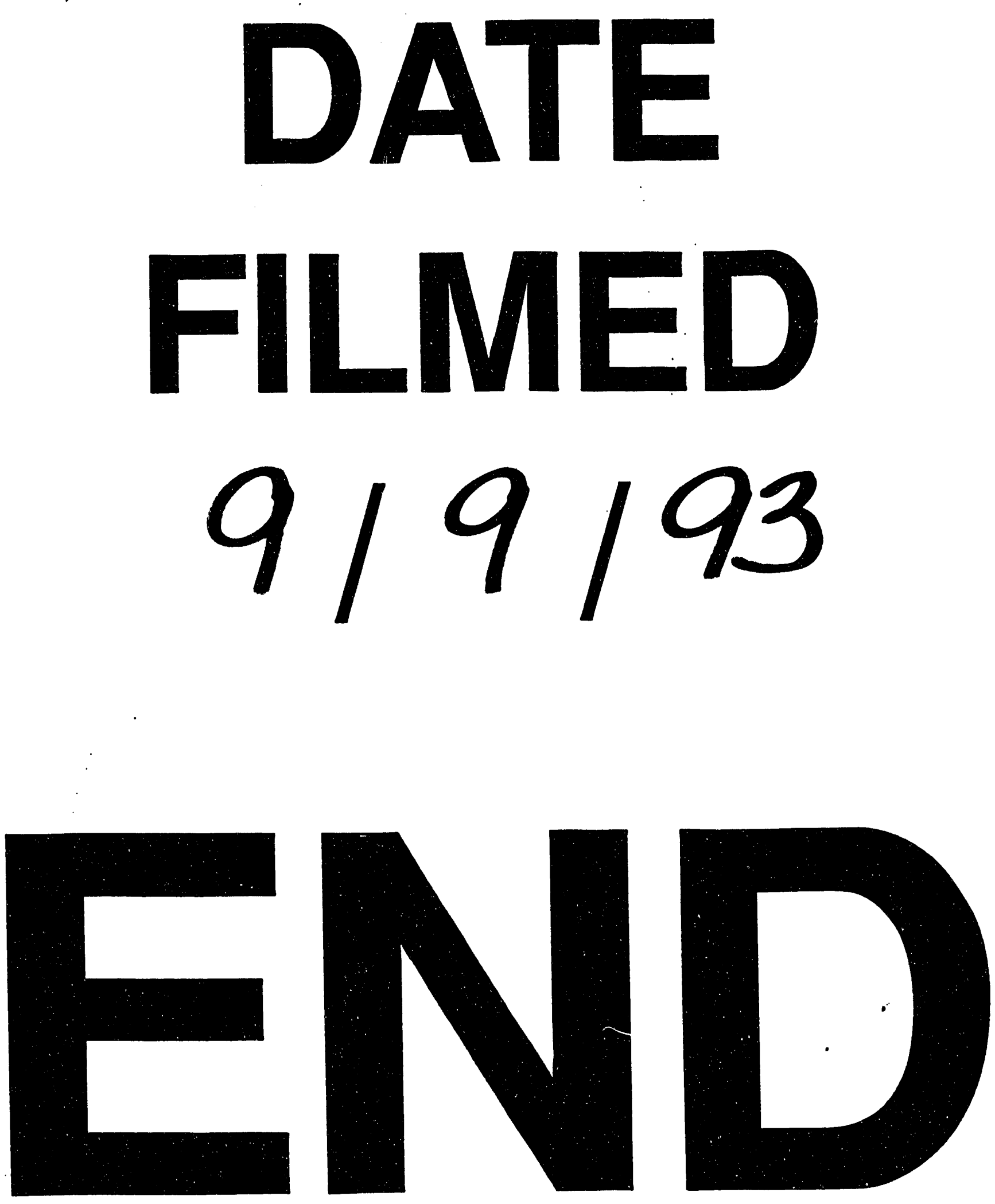


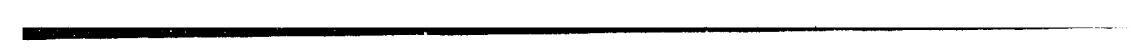

